\section{The American Association for Thoracic Surgery Journals}

\section{Seminars in Thoracic and Cardiovascular Surgery}

Seminars in Thoracic and Cardiovascular Surgery Editors Dr Harvey Pass and Dr Todd Rosengart would like to call your attention to several articles of interest in the next issue of the journal. "Discussions in Cardiothoracic Treatment and Care" features a roundtable on "TAVR" moderated by Dr Craig Smith with expert discussants Drs Vinod
Thourani, Michael Reardon, Charanjit Rihal, and Neil Moat debating the merits and pitfalls of TAVR and the future of cardiac intervention. The Editors also want to emphasize the "News and Views" article by Dr Bruce Ferguson on "The Affordable Care Act: Implications for Cardiac Surgery." Dr Ferguson explains the "ObamaCare" Act and its impact on the specialty - an important read for any cardiothoracic surgeon. The last highlighted article is a "Current Readings" contribution written by Dr William Rom from New York University on the most recent studies on bloodbased biomarkers for diagnosing lung cancer.

\section{The Western Thoracic Surgical Association}

\section{WTSA 40th Annual Meeting}

June 25-28, 2014

The St. Regis Monarch Beach

Dana Point, California

Visit the WTSA Web site at www.westernthoracic.org and:

- View the scientific and social programs;

- Register before the Monday, May 19, 2014, Early Bird deadline, and avoid a $\$ 100$ increase in most registration fees;

- Reserve your hotel room before the Saturday, May 24, 2014, housing deadline (although it is possible the block of rooms-or specific room types-set aside for the Western will fill before this cut-off date, so you are strongly encouraged to make your hotel reservations as soon as possible); and

- Get complete details on venue activities and local attractions.

\section{SCIENTIFIC HIGHLIGHTS}

Thursday, June 26, 2014

\section{Presidential Address}

Witness to the Wonder Years: Innovation to Transformation Thomas A. Burdon, Stanford, California

Friday, June 27, 2014

Postgraduate Course

Dave Williams, Newmarket, Ontario

\section{Invited Speaker Session}

Catheter-Based Mitral Valve Replacement: What Is It and Is It Possible?

Anson Cheung, Vancouver, British Columbia

Saibal Kar, Los Angeles, California
Saturday, June 28, 2014

Invited Speakers

Update on Pediatric VADs

Jonathan Michael Chen, Seattle, Washington

Simulations in Cardiac Surgery

Craig J. Baker, Los Angeles, California

James I. Fann, Stanford, California

\section{Walton Lillehei Point/Counterpoint Session}

Pay-for-Performance vs Criteria-Based Systems in the US and Canada

US: Jeffrey B. Rich, Norfolk, Virginia

Canada: Alan H. Menkis, Winnipeg, Manitoba

\section{SOCIAL HIGHLIGHTS:}

Each registration includes access to Wednesday's New Members/Welcome Reception, Thursday's Samson Fun Run and So-Cal Vintage Beach Party Theme Dinner, and Saturday's Family Luncheon and President's Banquet. (Registered children, ages 5-18, have access to supervised Children's Receptions during the New Members/Welcome Reception and President's Banquet.)

You may also supplement your Annual Meeting experience with these events:

- Thursday's Optional Tours*

- Friday's Golf Tournament*

- Friday's Tennis Tournament*

*Separate Registration Required

\section{ACCREDITATION}

This activity is being planned and implemented in accordance with the Essential Areas and Policies of the Accreditation Council for Continuing Medical Education (ACCME) through the joint sponsorship of the American Association for Thoracic Surgery (AATS) and the Western Thoracic 
Surgical Association (WTSA). The AATS is accredited by the ACCME to provide continuing medical education for physicians.
This live activity will be designated for AMA PRA Category 1 Credit $(s)^{\mathrm{TM}}$. Physicians should only claim credit commensurate with the extent of their participation in the activity.

\section{The AATS Graham Foundation}

\section{In Its 40th Year, the AATS Graham Foundation Announces New Specialty Programs}

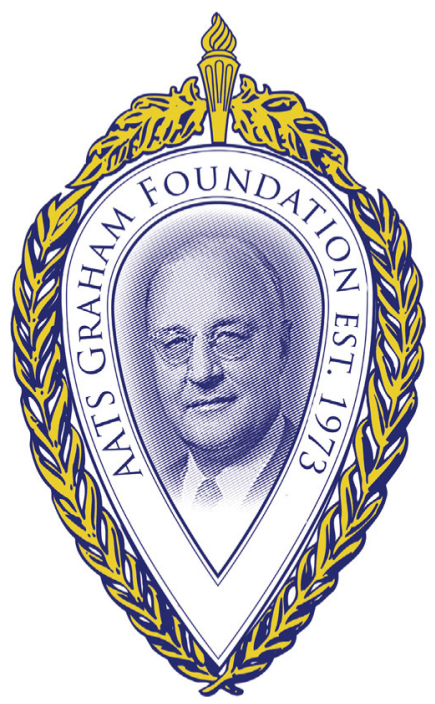

Over the past year, new fellowship programs for medical students, fellows, residents, and international professionals have been developed that provide specialized educational and training opportunities.
The Cardiothoracic Surgical Investigator Program caters to cardiothoracic surgeons interested in conducting clinical or translational research, while the Traveling Scholar Program provides young cardiothoracic surgeons from around the world a chance to study clinical techniques at a secondary institution.

Our new Resident Poster Session Scholarship for thoracic surgical residents has become extremely popular and competitive, along with the Critical Care Scholarship program that boasts over 50 students expected to participate in 2014 !

Along with our programmatic growth, we have engaged our Board of Directors to a full complement of eight, complete with two active board committees: Advisory Council headed by Dr Tim Gardner and Development Committee headed by Dr Raphael Bueno.

As our parent Association, the AATS underwrites all operational costs of the Foundation, allowing $100 \%$ of all individuals' contributions to go directly to Foundation programming.

The AATS Graham Research Foundation is driving leadership, learning and innovation in the pursuit of excellence! For more information on the AATS Graham Foundation, please visit http://aatsgrahamfoundation.org.

\section{Requirements for Maintenance of Certification}

Diplomates of the American Board of Thoracic Surgery (ABTS) who plan to participate in the Maintenance of Certification (MOC) process must hold an unrestricted medical license in the locale of their practice and privileges in a hospital accredited by the JCAHO (or other organization recognized by the ABTS). In addition, a valid ABTS certificate is an absolute requirement for entrance into the Maintenance of Certification process. If your certificate has expired, the only pathway for renewal of a certificate is to take and pass the Part I (written) and the Part II (oral) certifying examinations. The names of individuals who have not maintained their certificate will no longer be published in the American Board of Medical Specialties Directories. Diplomates' names will be published upon successful completion of the Maintenance of Certification process.

The CME requirements are 30 Category I credits earned during each year prior to application. At least half of these CME hours need to be in the broad area of thoracic surgery. Category II credits are not allowed. Interested individuals 